\title{
Investigation of the intraseasonal oscillations over a Brazilian equatorial station: a case study
}

\author{
Amitava Guharay ${ }^{1 *}$, Paulo Prado Batista ${ }^{1}$, Barclay Robert Clemesha', Sumanta Sarkhel ${ }^{2}$ and Ricardo Arlen Buriti ${ }^{3}$
}

\begin{abstract}
Characteristics of the intraseasonal oscillations (ISO) in the mesosphere and lower thermosphere (MLT) are investigated using meteor radar wind observations from a South American, equatorial station, São João do Cariri $\left(7.4^{\circ} \mathrm{S}, 36.5^{\circ} \mathrm{W}\right)$ during 2008. A prominent ISO signature is observed during January-May in the period band approximately 40 to 70 days in the MLT zonal wind. In the lower atmosphere, a dominant ISO is observed in the period band approximately 30 to 60 days in the outgoing longwave radiation (OLR) (a proxy for convection), total columnar water vapor (a proxy for tides), and zonal wind. Considerable high correlation of the ISO between the MLT and lower atmosphere indicates significant dynamical coupling between the lower and middle atmosphere during the observational period. The MLT-ISO shows conspicuous downward propagation of the peak amplitude indicating the role of the dissipating upward propagating waves for its generation. The amplitudes in the zonal wind of the dominant tidal components in the MLT exhibit conspicuous ISO modulation. The eastward propagating waves and tides are surmised to be responsible for communicating the ISO signature from the lower atmosphere to the MLT. The origin of the MLT-ISO is believed to take place in the lower troposphere, below $4 \mathrm{~km}$. The MLT-ISO is believed to be the imprint of the lower atmospheric Madden-Julian oscillation which travels eastward from the Indian Ocean-western Pacific Ocean to the present location.
\end{abstract}

Keywords: Intraseasonal oscillations; Lower and middle atmosphere coupling; Meteor radar observations

\section{Background}

The mean dynamical state of the equatorial middle atmosphere is significantly controlled by large-scale long period oscillations, i.e., semiannual oscillations (SAO) and quasibiennial oscillations (QBO) (Burrage et al. 1996; Baldwin et al. 2001; Guharay et al. 2014a). These oscillations show downward propagation of their phases with altitude since they are driven by deposition of energy from upward propagating gravity waves, Rossby waves, Kelvin waves, etc. due to wave-mean flow interaction. Convective processes are believed to be the most important mechanism for driving these waves which cause the strong SAO and $\mathrm{QBO}$ in the stratosphere and comparatively weak oscillations in the mesosphere.

In addition to the aforesaid long period oscillations, the equatorial lower and middle atmosphere wind exhibits significant oscillations in the period range 20 to 100 days which are termed as instraseasonal oscillations (ISO). The ISO was first observed by Eckermann and

\footnotetext{
* Correspondence: guharay@hotmail.com

${ }^{1}$ National Institute for Space Research, INPE, São José dos Campos, SP, Brazil Full list of author information is available at the end of the article
}

Vincent (1994) in the mesosphere and lower thermosphere (MLT) zonal wind in the period range 10 to 100 days with dominant periodicities in the bands approximately 60,35 to 40,20 to 25 days using medium-frequency (MF) radar at Christmas Island $\left(2^{\circ} \mathrm{N}, 157^{\circ} \mathrm{W}\right)$. They reported a striking similarity of the observed ISO in the MLT with their tropospheric counterpart, i.e., Madden-Julian oscillation (MJO) as described by the earlier investigators (Madden and Julian 1971, 1972). Later, Eckermann et al. (1997) furthered the work with nearly 5 years of long-term data and reported dominant ISO in the MLT zonal wind at Christmas Island with periods approximately 60, 40, and 20 days. They also found strong ISO modulation of the gravity waves and diurnal tide.

The MJO in the equatorial troposphere is observed in the zonal wind and rainfall which is driven by the convective anomalies transpiring in the regions near the Indian Ocean and western and central Pacific Ocean (Madden and Julian 1971). Large-scale convective anomalies are generated over the tropical Indian Ocean and slowly propagate with diminishing strength through the western and central Pacific Ocean and later disappear in the 
eastern Pacific Ocean (Madden and Julian 1972). The MJO can be interpreted as a mixed Kelvin and Rossby waves near the source region and an eastward propagating Kelvin wave away from the source (Madden and Julian 1994). The MJO feature in the zonal wind exhibits an outof-phase relationship in the lower and upper troposphere, and it decays drastically above the tropopause (Madden and Julian 1971, 1972). Signatures of the MJO were also observed in the ocean heat flux and sea surface temperature which was inferred as being a result of interaction between the convective processes and largescale circulations in the troposphere (Jones et al. 1998).

Although the MJO is a large-scale feature in the equatorial tropospheric zonal wind, it cannot propagate vertically upward to the MLT region due to its low phase speed (Eckermann et al. 1997). Eckermann et al. (1997) suggested that the MJO-modulated tropospheric convection causes similar modulation of the intensity of the upward propagating gravity waves and nonmigrating diurnal tide, and as these waves break/dissipate in the MLT region, they drive intraseasonal variation in the ambient wind. Kumar and Jain (1994) inferred that the tropospheric Rossby waves responsible for the MJO in the troposphere can propagate directly to the upper atmosphere. On the other hand, with global geopotential height observations, Ziemke and Stanford (1991) argued that the upward propagating Rossby waves from the tropical region travel towards midlatitude and refract back to the tropical latitude near the stratopause and imprint the ISO of 1- to 2-month periods over Indian Ocean-western Pacific region. Recently, Niranjankumar et al. (2011) found a signature of refraction of the tropical ISO through subtropical stratosphere in course of propagation from the lower to the middle atmosphere over an Indian tropical station, Gadanki $\left(13.5^{\circ} \mathrm{N}, 79.2^{\circ} \mathrm{E}\right)$ which was supported by the most recent study by Guharay et al. (2014b) utilizing observations from two low latitude Brazilian stations.

Using the satellite-based high-resolution Doppler imager (HRDI), Lieberman (1998) studied the MLT-ISO in the zonal mean zonal wind at $\pm 20^{\circ}$ latitude region and found maxima at 121, 72, and 33 days. They reported significant modulation of the gravity waves and tides by the ISO supporting the earlier findings of Eckermann et al. (1997). Using radar wind observations over Jakarta $\left(6^{\circ} \mathrm{S}, 107^{\circ} \mathrm{E}\right)$, Pontianak $\left(0^{\circ} \mathrm{N}, 109^{\circ} \mathrm{E}\right)$ and Christmas Island, Isoda et al. (2004) inferred that the mesospheric ISO is not a feature of propagating disturbances; rather, it is a variation of the zonal mean flow. They observed clear ISO modulation of the MLT zonal wind and diurnal tidal amplitude implying an appreciable contribution of the diurnal tide originating from the lower atmosphere to the MLT-ISO. They also found biennial variability in the ISO amplitude of the zonal wind and zonal amplitude of the diurnal tide. Using global circulation model study, Miyoshi and Fujiwara (2006) showed important role of ultrafast Kelvin wave and diurnal tide (migrating and nonmigrating) on excitation of the MLTISO. Recently, Kumar et al. (2007) reported ISO in the MLT zonal wind over the Indian sector, Tirunelveli $\left(8.7^{\circ} \mathrm{N}, 77.8^{\circ} \mathrm{E}\right)$ in two period bands approximately 50 to 70 days and 20 to 40 days which were consistent with the observed ISO in the outgoing longwave radiation (OLR) and water vapor, respectively. Rokade et al. (2012) carried out a comparative study with radar wind observations from two Indian low latitude stations and found influence of the deep tropical convection on the variability of the observed MLT-ISO. Most recently, using 3 years of observations, Guharay et al. (2012) showed existence of a dominant ISO in the period range 20 to 100 days at Gadanki $\left(13.5^{\circ} \mathrm{N}, 79.4^{\circ} \mathrm{E}\right)$ with intermittent behavior in the troposphere, insignificant amplitude in the stratosphere, and consistent variability in the mesosphere.

Although a number of investigations of the ISO carried out over Indian Ocean-western pacific sector (convective anomaly source region) are available, observations from the South American region (away from the sources) are scarce. Recently, Rao et al. (2009) studied longitudinal variability of the ISO using measurements over four equatorial stations located at different longitudinal sectors over the globe including the present site, but the study did not investigate the generation mechanism in detail. Therefore, in our present paper, we have studied the characteristics of the MLT-ISO at São João do Cariri (hereafter referred to as Cariri) $\left(7.4^{\circ} \mathrm{S}, 36.5^{\circ} \mathrm{W}\right)$, its correspondence with the lower atmospheric counterpart, i.e., MJO, as well as the possible generation mechanism for excitation in the lower and middle atmosphere. It should be mentioned that the most coherent ISO feature over various atmospheric regions at the present station is found during early 2008 (not observed in other years), and hence, we have selected the year 2008 for the present study.

\section{Instruments and database \\ Meteor radar wind}

The horizontal winds utilized for the present study are obtained from a SKiYMET-type meteor radar installed at Cariri. The radar operates at a frequency of $35.24 \mathrm{MHz}$ with pulse width $13 \mu \mathrm{s}$, peak power $12 \mathrm{~kW}$, and pulse repetition frequency $2,144 \mathrm{~Hz}$. It employs one threeelement Yagi antenna for transmission. For receiving the backscattered signal from the meteor trails, it uses fivephase coherent two-element Yagi antennas aligned along two orthogonal baselines with one center antenna common to both. The radar is able to detect about 5,000 meteor echoes per day to derive angular position, range, and wind velocity components. The details of the derivation 
algorithm for estimating the horizontal winds can be found in the paper of Hocking et al. (2001). For the present work, we have used zonal and meridional winds of temporal resolution $1 \mathrm{~h}$ and vertical resolution of $3 \mathrm{~km}$ within the vertical range 81 to $99 \mathrm{~km}$ for the year 2008 . Daily mean winds estimated from the hourly values are used for determining the ISO characteristics in the MLT.

\section{ERA-Interim database}

In order to estimate the ISO features in the stratosphere and troposphere, we have utilized the ERA-Interim reanalysis database (Berrisford et al. 2009) available at $0.5^{\circ} \times$ $0.5^{\circ}$ latitude-longitude grid provided by the European Centre for Medium-range Weather Forecasts (ECMWF) during the observational period. For the present purpose, we have used daily zonal wind at 37 pressure levels ( 1 to $1,000 \mathrm{hPa}$ ), i.e., 0 to $48 \mathrm{~km}$ altitude range at grid point $7.5^{\circ} \mathrm{S}, 36.5^{\circ} \mathrm{W}$ nearest to the location of Cariri. Data of the total columnar water vapor (TCWV) at $7.5^{\circ} \mathrm{S}, 36.5^{\circ} \mathrm{W}$ during the observational period are also utilized for studying the ISO activity. Furthermore, 10-m zonal wind is used as a proxy for surface wind (Foltz and McPhaden 2004) for the latitude range $10^{\circ} \mathrm{N}$ to $10^{\circ} \mathrm{S}$ and longitude range 0 to $360^{\circ} \mathrm{E}$.

\section{OLR database}

To investigate the convective activity during the observational period, we have utilized OLR data available at $2.5^{\circ} \times 2.5^{\circ}$ latitude-longitude grid provided by the National Centers for Environmental Prediction (NCEP) as a proxy in the year 2008. Details of the OLR data can be found in the available literature (Kalnay et al. 1996). OLR data for the latitude range $10^{\circ} \mathrm{N}$ to $10^{\circ} \mathrm{S}$ and longitude range 0 to $360^{\circ} \mathrm{E}$ are considered for the present work. The closest available OLR grid point to Cariri is found to be $7.5^{\circ} \mathrm{S}, 37.5^{\circ} \mathrm{W}$.

\section{Methods}

For studying the ISO in the lower atmosphere and MLT, we utilized the standard wave analysis tools. These include Lomb-Scargle periodogram, wavelet analysis, digital filter, and cross-correlation analysis.

\section{Results}

In order to find out the ISO signature in the MLT winds, we have estimated the Lomb-Scargle periodogram at each altitude bin of the meteor radar-derived daily mean zonal and meridional winds in the range 81 to $99 \mathrm{~km}$ in 2008 which are plotted in Figure 1a, b. The zonal wind spectrum shows a very sharp amplitude peak near the period approximately 30 to 32 days within the altitude range 84 to $93 \mathrm{~km}$. Another broad maximum of comparative lesser amplitude is found to be very prominent near periods approximately 45 to 70 days below $90 \mathrm{~km}$.

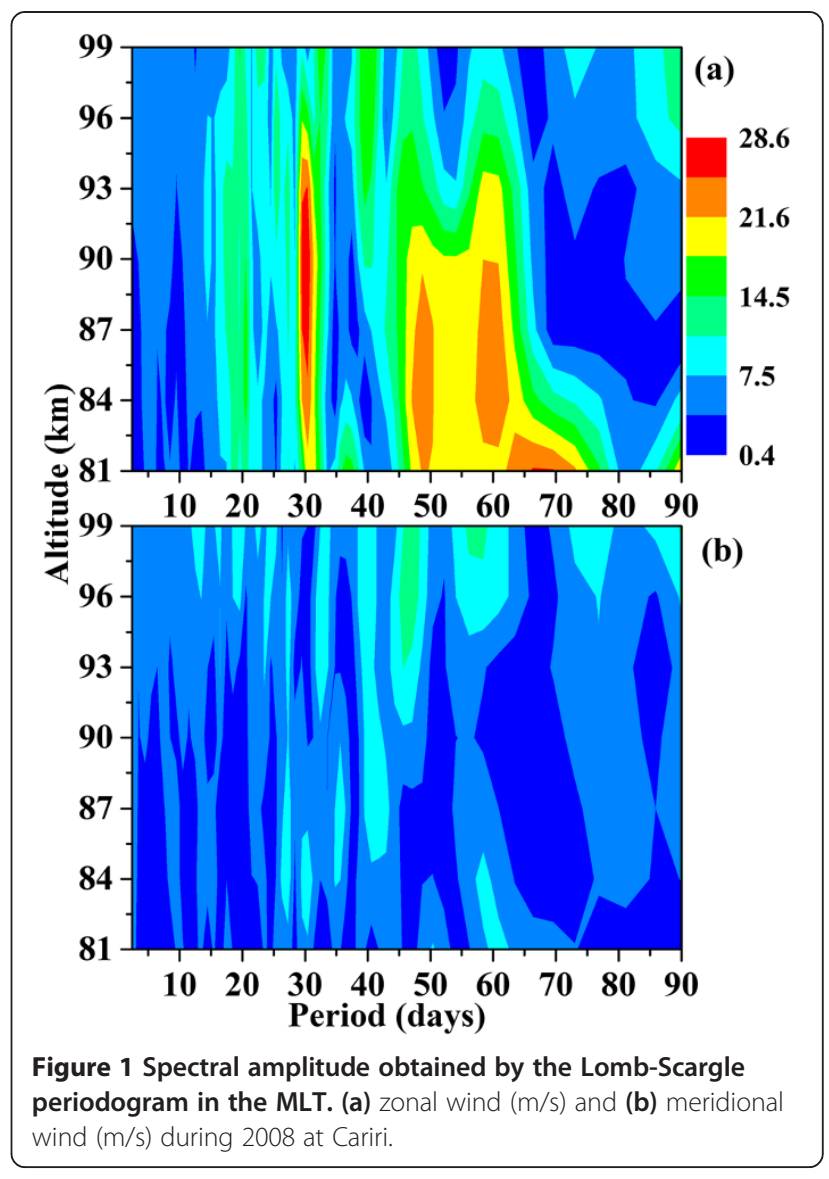

On the contrary, the meridional wind spectrum does not show any significant peak within the ISO band implying the existence of the ISO feature in the zonal wind only. Therefore, in all the following sections, we will only consider the zonal wind for detailed study of the ISO at Cariri.

In order to look into the time variation of the dominant periodicities of the ISO, we have estimated the wavelet spectra in terms of the spectral power using Morlet as a mother wavelet in the zonal wind. The wavelet power spectra are adjusted by rectifying the frequencydependent bias similar to the method of Liu et al. (2007). The analysis is performed for the mid-lower MLT altitudes (81 to $90 \mathrm{~km}$ ) since the observed spectral components are found to be dominant in this range. Figure 2a, b, c, d shows the adjusted wavelet spectra at $90,87,84$, and $81 \mathrm{~km}$, respectively. The bold lines in all subplots denote $95 \%$ significance level. In addition to small periodicities ( $<10$ days), the spectra are dominated by a period band centered at 20 days. Wavelet spectrum at $81 \mathrm{~km}$ shows dominant component centered around the period approximately 30 days during 120 to 160 day of the year (DY). All the spectra show a dominant common period band of approximately 40 to 70 days during the time span 1 to 120 DY. It can be 


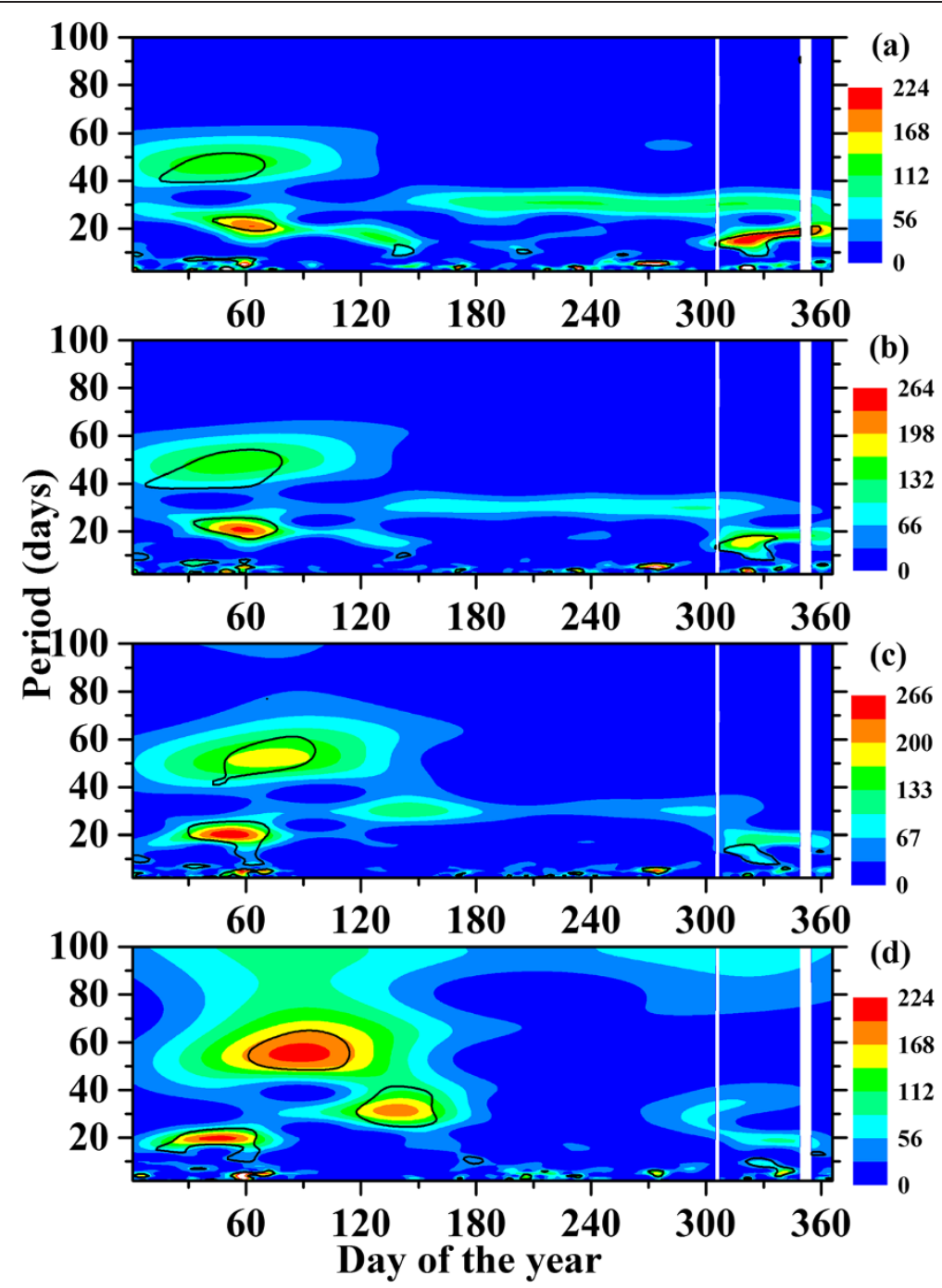

Figure 2 Adjusted wavelet spectra of the zonal wind in terms of the spectral power (m²/ $\mathbf{s}^{2} /$ day). At (a) $90 \mathrm{~km}$, (b) $87 \mathrm{~km}$, (c) $84 \mathrm{~km}$, and (d) $81 \mathrm{~km}$ at Cariri. The bold lines denote 95\% significance level.

noted that the central peak of this broad spectral band moves from approximately 45 to 60 days (period) from 90 to $81 \mathrm{~km}$ implying a shift of the dominant ISO period with the altitude. Another feature evident is shift of the band center from approximately $50 \mathrm{DY}$ at $90 \mathrm{~km}$ to approximately $90 \mathrm{DY}$ at $81 \mathrm{~km}$ indicating a prominent downward phase propagation of vertical phase speed of approximately $225 \mathrm{~m} /$ day. Therefore, the spectra in the MLT clearly show the dominance of the ISO in the period range 30 to 70 days.

To find the ISO features in the lower atmosphere, we have calculated the adjusted wavelet spectra of daily values of OLR (Figure 3a), TCWV (Figure 3b), ERAInterim zonal wind at $150 \mathrm{hPa}$ (Figure 3c) and ERAInterim surface zonal wind (Figure 3d) at Cariri. The OLR spectrum exhibits a significant peak at period approximately 30 to 40 days near 60 to $110 \mathrm{DY}$ indicating a considerable influence of convective activity on the ISO. The small peaks of period less than 20 days found at various times of the year are possibly due to Rossby and/or Kelvin waves. The TCWV spectrum shows a dominant spectral peak of period approximately 50 to 60 days during the initial 120 DY. Since water vapor is the most important atmospheric species producing tides in the lower and middle atmosphere, there is an indication of the tidal involvement in the observed ISO signature. The zonal wind spectrum at $150 \mathrm{hPa}$ (upper troposphere) shows a clear peak near the period of approximately 40 days during 1 to $60 \mathrm{DY}$. The spectrum of the surface zonal wind exhibits a dominant peak of period approximately 50 to 60 days during 30 to 120 DY. Therefore, all the selected lower atmospheric variables indicate prominent ISO signatures in the period band 40 to 60 days during initial 120 days of the year suggesting a 


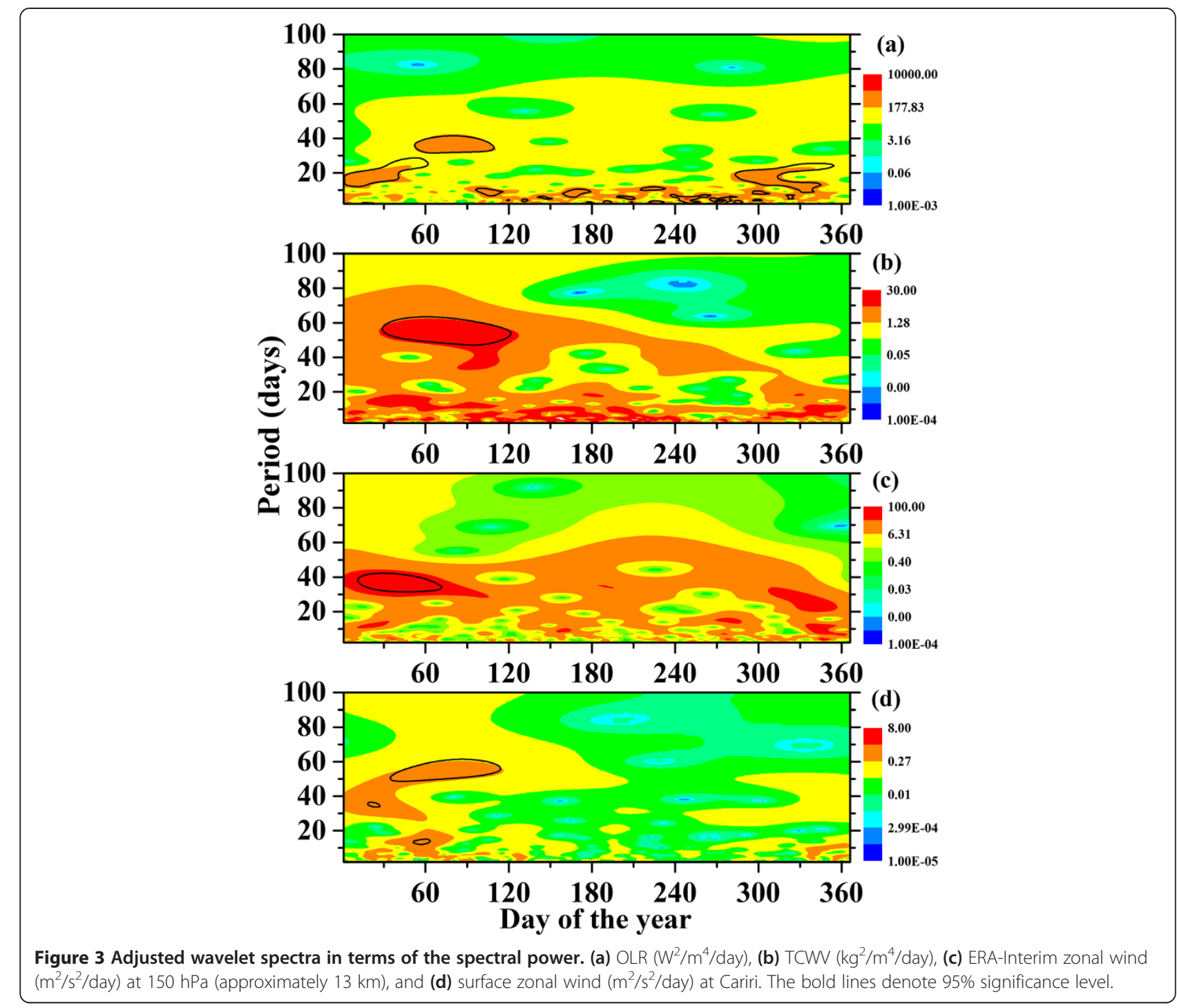

good correspondence with the observed MLT-ISO in the period range 30 to 70 days.

In order to characterize the vertical structure of the ISO, we have shown the filtered profiles of the zonal wind within the band 30 to 70 days in the MLT and troposphere-stratosphere (TS) in Figure $4 \mathrm{a}, \mathrm{b}$. The filtered zonal wind in the MLT shows maximum amplitude near 60 DY in the mid and lower MLT. Subsequently, the ISO amplitude shows a decay over time which starts from the higher altitudes and progresses towards the lower altitude with time and reaches lower MLT near 150 DY. The ISO activity re-intensifies at $90 \mathrm{~km}$ around 180 DY and remains relatively smaller during rest of the year. The ISO in the TS shows appreciable activity near the upper troposphere (10 to $17 \mathrm{~km}$ ) consistent over the year. The ISO activity is not prominent above the troposphere up to the stratopause most of the time except during the span approximately 120 to $270 \mathrm{DY}$ in the upper stratosphere. The high ISO amplitude during 120 to $270 \mathrm{DY}$ interval in the upper stratosphere is possibly due to the downward propagation of the mesospheric ISO. Unfortunately, we do not have observational data in the mesosphere region (50 to $80 \mathrm{~km}$ ) to verify this.

To compare the ISO behavior in the MLT and the lower atmosphere, we have shown the filtered profiles of the zonal wind at $81 \mathrm{~km}$, OLR, TCWV, and surface wind within the 30 to 70 days band in Figure 5a. The surface wind and TCWV are scaled by a factor of 20 and 4, respectively, for better clarity of the variation. The common feature is higher amplitude of all the variables during 1 to $150 \mathrm{DY}$. Less coherence in the observed phases of the ISO among various variables is due to the difference in the spectral components within the selected band. The cross correlation coefficient of the ISO between the MLT and TS during the interval 1 to 150 DY is shown in Figure $5 \mathrm{~b}$ using the same variables as 


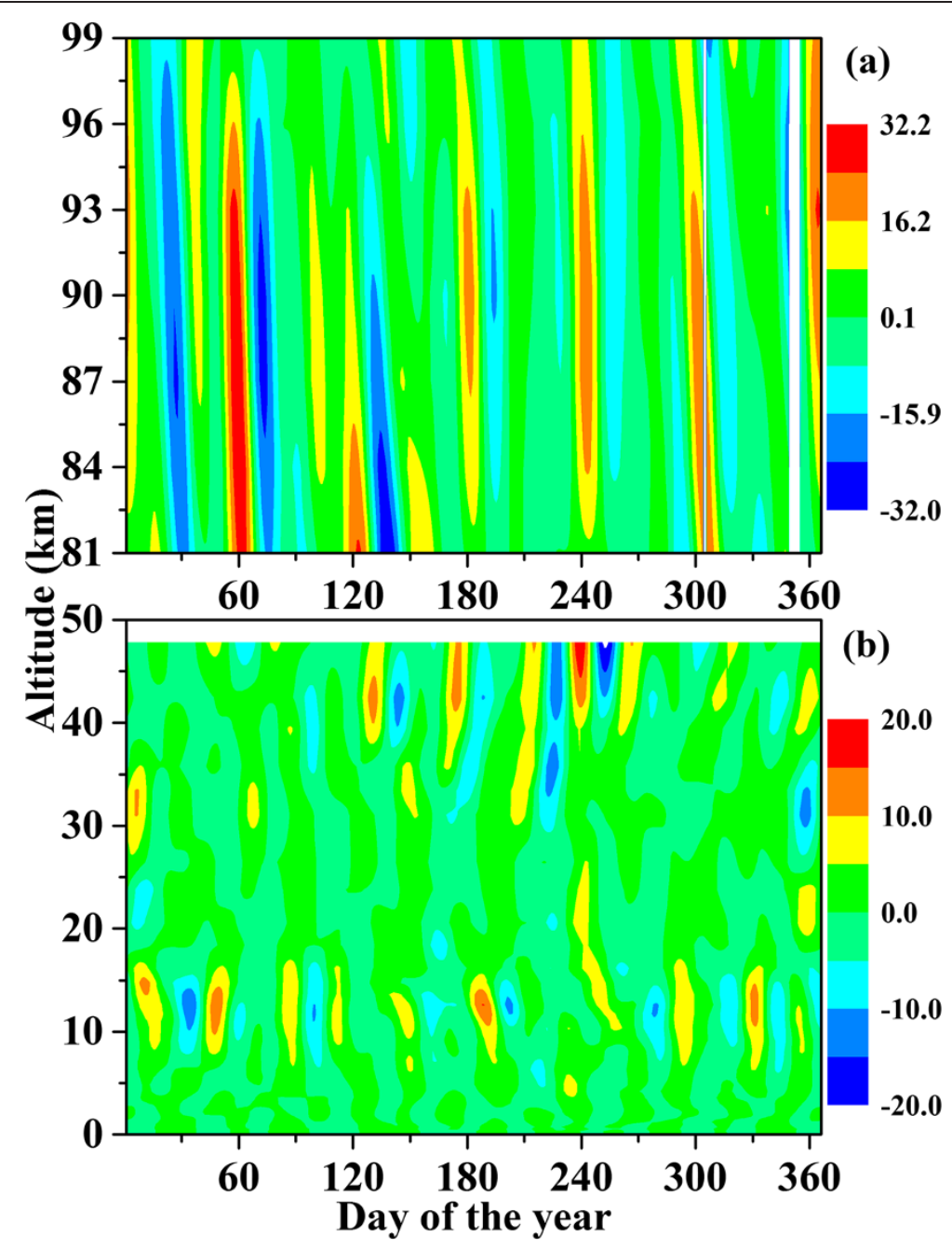

Figure 4 Filtered zonal wind (m/s) in the period range 30 to 70 days in the (a) MLT, and (b) TS.

Figure 5a. The maximum cross-correlation coefficient is found to be 0.79 between the zonal wind at $81 \mathrm{~km}$ and TCWV with a lag of -32 days. Between the zonal wind at $81 \mathrm{~km}$ and surface wind, it is around 0.72 with a lag of -30 days. The correlation is found to be smaller (approximately 0.35 ) in between the zonal wind at $81 \mathrm{~km}$ and OLR with a lag of -33 days. Therefore, high correlation $(>0.5)$ of the zonal wind at $81 \mathrm{~km}$ with the TCWV may suggest a contribution of the atmospheric tides to the lower and middle atmospheric coupling evident through the ISO.

The relationship between the MLT-ISO and TS-ISO with respect to altitude is further investigated by studying the correlation between the filtered zonal wind in the MLT (meteor radar wind) and TS (ERA-Interim wind) during the interval 1 to 150 DY. Figure 6 shows the vertical profiles of the maximum cross-correlation coefficient in the TS obtained by correlating with MLT zonal winds at $90,87,84$, and $81 \mathrm{~km}$ individually. The plot clearly shows maximum correlation values below $4 \mathrm{~km}$, and the correlation generally diminishes with the MLT altitude. Another evident feature is alternate enhancement (at approximately 10, 22, 33, $48 \mathrm{~km}$ ) and diminution (at approximately 15, 25, $40 \mathrm{~km}$ ) of the correlation coefficients with the TS altitude suggesting an intermittent relationship of the ISO between the MLT and TS.

In order to understand the lower atmospheric MJO anomaly propagation characteristics, we have shown the longitude-time profiles of the OLR and surface zonal wind filtered spatially for wavenumbers 1 to 6 and temporally for 30 to 70 days within the mean latitudinal range of $10^{\circ} \mathrm{N}$ to $10^{\circ} \mathrm{S}$ in Figure $7 \mathrm{a}, \mathrm{b}$. The source region, i.e., maximum MJO anomaly amplitude is found near 60 to $200^{\circ} \mathrm{E}$ which is dominant with larger longitudinal extent during the first 150 days of the year. Both the plots show prominent eastward phase propagation of the MJO anomaly with time. The estimated phase speeds near the 

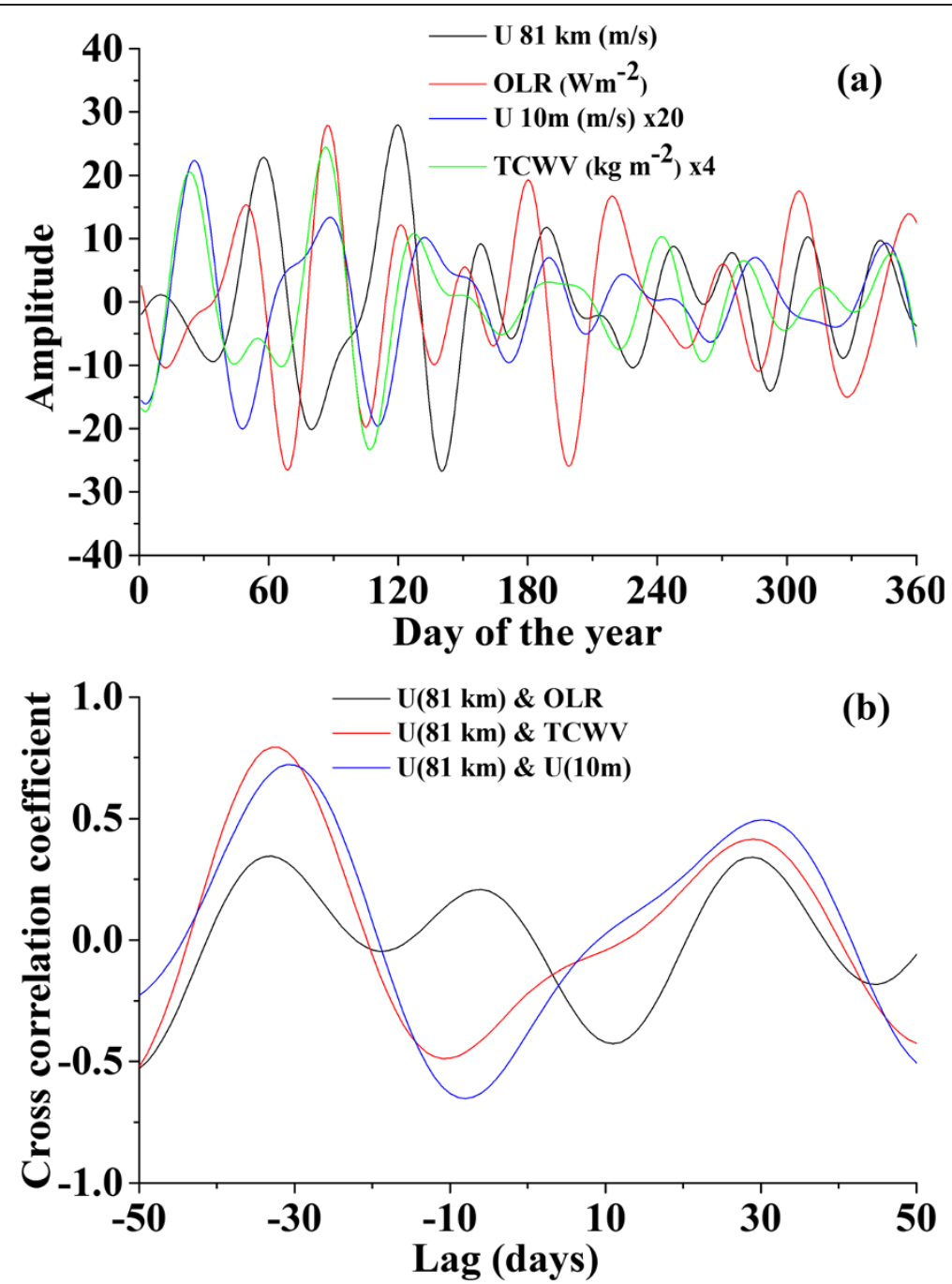

Figure 5 Filtered and cross-correlation coefficient profiles. (a) Filtered profiles in the period range 30 to 70 days of the zonal wind at $81 \mathrm{~km}$, OLR, surface zonal wind, TCW, and (b) cross-correlation coefficient for various lags.

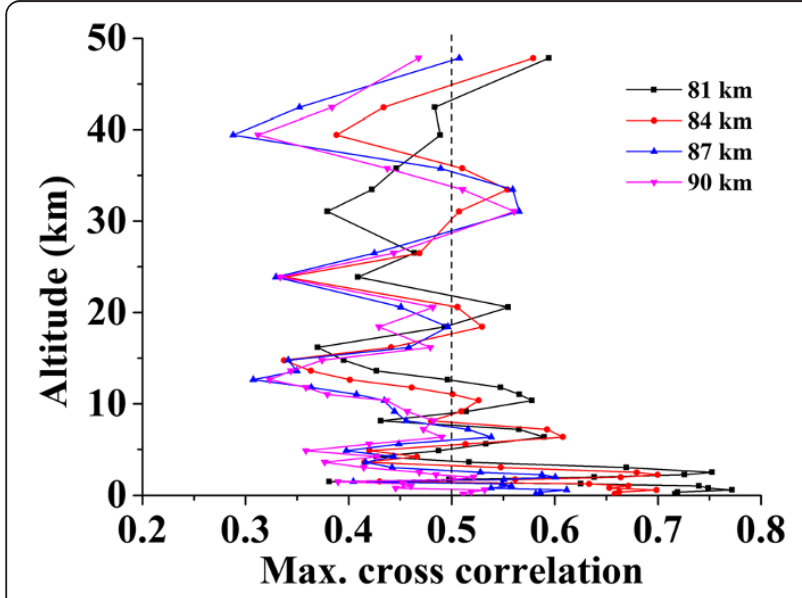

Figure 6 Maximum cross-correlation coefficient. Between the MLT-ISO (radar zonal wind at 90, 87, 84 and $81 \mathrm{~km}$ ) and the TS- ISO (ERA-Interim zonal wind) at Cariri during 2008. source region along the arrows shown in the plots come out to be approximately 3.7 and $5.7 \mathrm{~m} / \mathrm{s}$ for the OLR and surface zonal wind, respectively. Therefore, the signature of the MLT-ISO in the present longitude sector $\left(323.5^{\circ} \mathrm{E}\right)$ can be conceived as being driven by the eastward propagating $\mathrm{MJO}$ anomaly originating from the Indian Ocean-western Pacific Ocean with diminishing amplitude. However, the amplitude at the present longitude in both OLR and surface zonal wind is observed to be significantly smaller than at the source region.

We have estimated the daily tidal amplitudes of the diurnal, semidiurnal, and terdiurnal tides using the least square fit method as described by Guharay et al. (2013a) for the temporal span 1 to 150 DY. Further to elucidate the possible role of the tides on the observed MLT-ISO, we have calculated the Lomb-Scargle spectra of the daily amplitudes of the diurnal, semidiurnal, and terdiurnal 


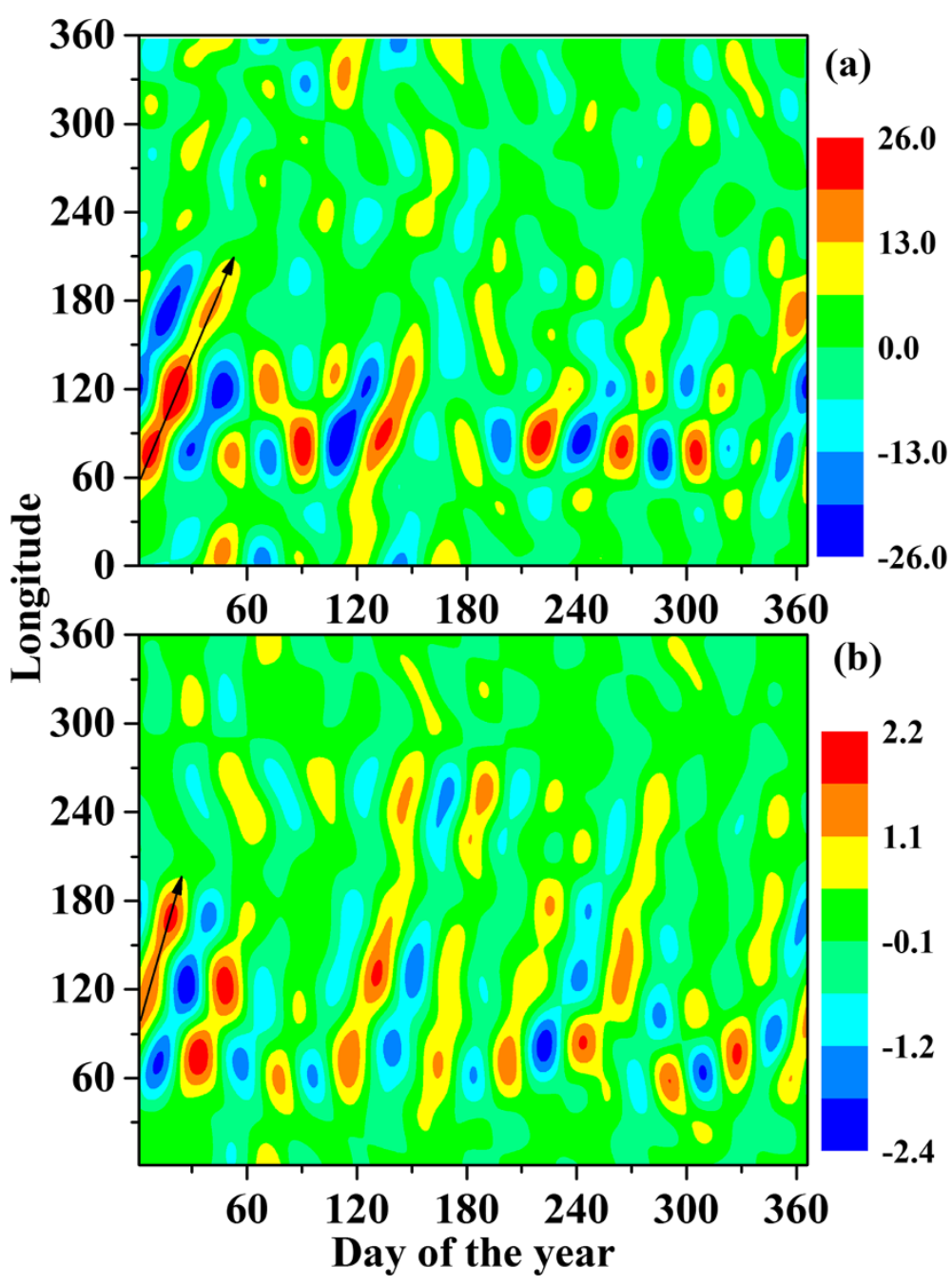

Figure 7 Filtered OLR and surface zonal wind. (a) Filtered OLR $\left(\mathrm{W} / \mathrm{m}^{2}\right)$ and (b) filtered surface zonal wind (m/s) within the spatial range 1 to 6 wavenmuber and temporal range 30 to 70 days.

tide. The tidal spectra in terms of the normalized power at $90,87,84$, and $81 \mathrm{~km}$ are shown in Figure $8 \mathrm{a}, \mathrm{b}, \mathrm{c}$. The diurnal tide spectrum shows prominent peaks near 38 to 55 days in addition to the dominant peaks near 12 to 22 days. The semidiurnal tide shows a dominant peak near 25 to 30 days and an insignificant peak near 50 to 55 days. The terdiurnal tide shows significant peaks near 20 and 70 days which are smaller as compared to the diurnal and semidiurnal tides. Therefore, from the periodograms, one can note an evident tidal relationship with the present ISO activity in the period band 30 to 70 days.

\section{Discussion}

The present study from an equatorial South American station (away from the convective anomaly region) reveals a prominent ISO signature in the period range approximately 40 to 70 days in the MLT region during
January-May of the year 2008. The detailed study of the ISO reveals its significant relationship with the lower atmospheric MJO suggesting its origin at lower troposphere, and it should be mentioned that such relationship is not prominent in the available limited dataset.

The ISO amplitude is found to be appreciable near the upper troposphere, stratopause, and mid-lower MLT. The ISO originating in the troposphere cannot propagate directly up to the mesosphere due to their small phase speed. The waves with higher phase speed originating from the lower atmosphere are modulated by the ISO and carry their signature to the middle atmosphere. As they break/dissipate in the middle atmosphere, the ISO signature reappears in the mean flow variability. In the MLT, we have found a shift of the peak period towards lower values with altitude. In general, the high frequency waves with higher phase speed can propagate to higher altitudes as compared to their low frequency 


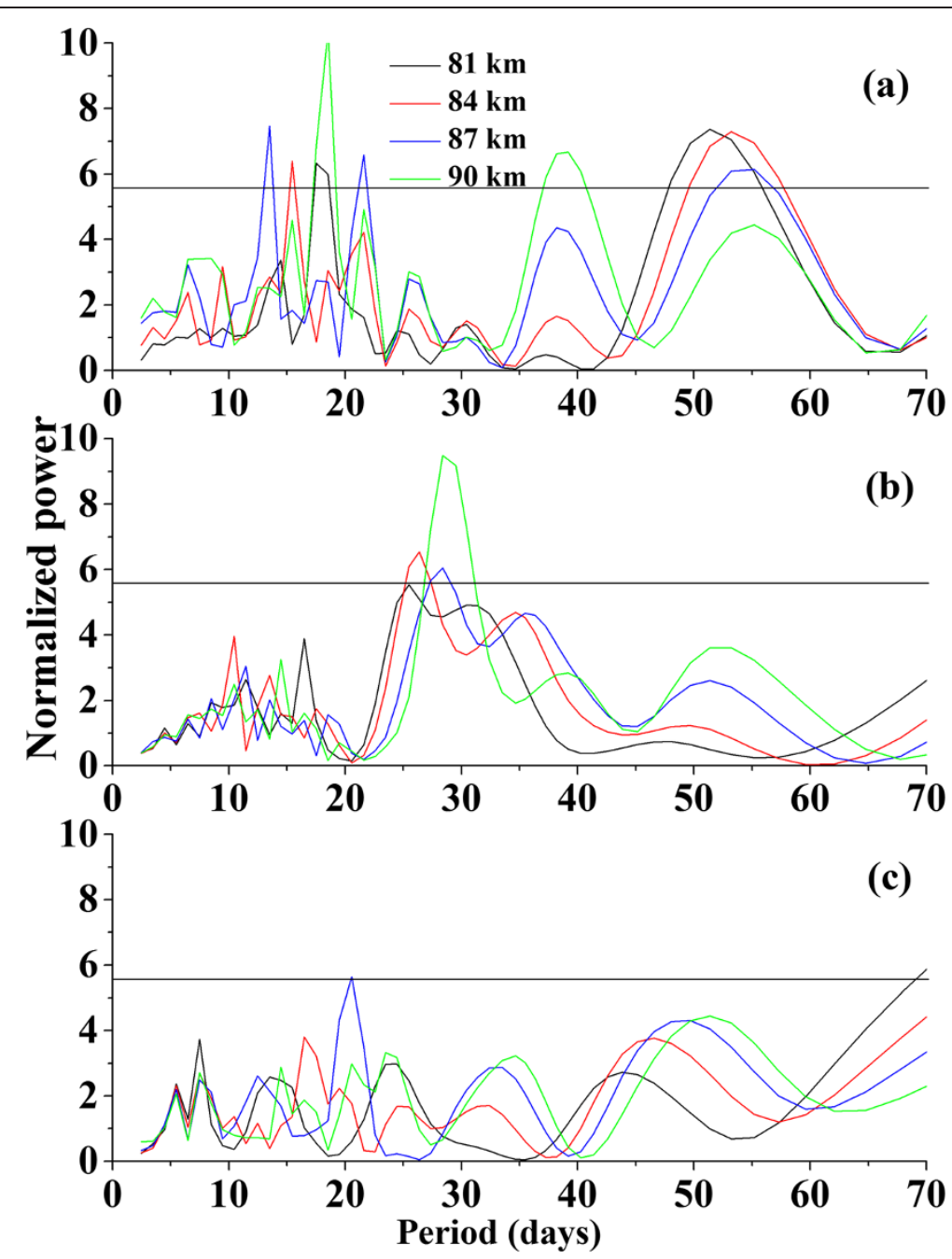

Figure 8 The Lomb-Scargle periodogram of the tidal ampltiudes. (a) Diurnal tide, (b) semidiurnal tide, and (c) terdiurnal tide during 2008. The horizontal lines represent 95\% significance level.

counterpart before they deposit their energy due to breaking/dissipation causing the appearance of the high frequency ISO at higher altitudes.

In the MLT, wavelet (Figure 2) profiles show clear downward propagation of the ISO peak amplitude supporting the notion of its generation by dissipation of the upward propagating waves. With satellite-based HRDI observations, Lieberman (1998) observed prominent downward propagation of the ISO in the MLT and he inferred significant role of gravity waves in driving the ISO. The observational results of the present study support the inference of Lieberman (1998).

To look into the wave filtering by the background wind, we have shown the mean zonal wind profiles at Cariri averaged over the temporal span 1 to 150 DY in the MLT and TS in Figure 9a, b. Evident from the plot is the dominant westward wind implying preferential filtering of the eastward propagating waves. The eastward wind is observed only within the altitude range approximately 10 to $16 \mathrm{~km}$. It should be noted that the filtered profile (Figure 4) shows strong ISO feature near this range which is most probably due to the dissipation of the eastward waves. In the mesosphere, the eastward propagating waves which are believed to produce the ISO signature break/dissipate due to persistent convective and/or dynamical instability. Therefore, we can infer that the eastward propagating waves, i.e., gravity waves, nonmigrating tides, Kelvin waves, etc. are the most likely drivers of the ISO at Cariri. Using long-term MF radar observations from Tirunelveli, Sridharan et al. (2007) reported strong ISO activity during the westward phase of the zonal background wind consistent with the present findings. In this context, it should be mentioned that Madden and Julian (1994) suggested that the MJO could be considered as eastward propagating Kelvin waves away from the source region. In a very recent study, 


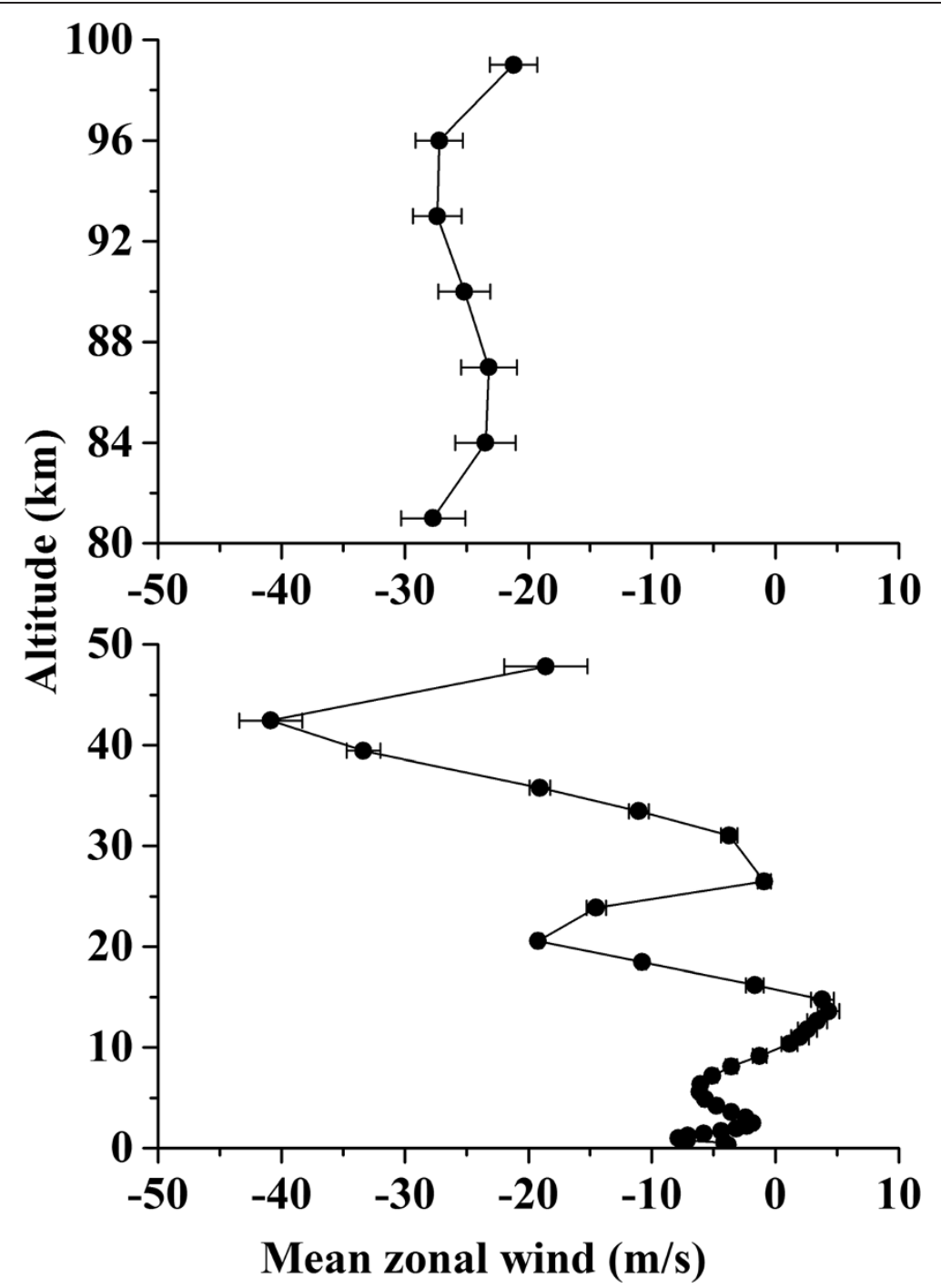

Figure 9 Mean zonal wind during the temporal span 1 to 150 DY in the (a) MLT and (b) TS. The horizontal bars denote standard error.

using meteor radar zonal wind observations from an extratropical Brazilian station, Cachoeira Paulista $\left(22.7^{\circ} \mathrm{S}\right.$, $\left.45^{\circ} \mathrm{W}\right)$, Guharay et al. (2013b) found intraseasonal modulation of the eastward propagating ultra-fast Kelvin wave amplitude in the MLT.

Convection is the most important driver of the various atmospheric waves in the lower atmosphere (Manzini and Hamilton 1993; Hagan and Forbes 2003; Alexander et al. 2006). Since the convective activity is modulated by the ISO, the intensity of the convection-driven waves is also modulated by the ISO (Eckermann et al. 1997). Therefore, common intuition expects good correlation of the ISO between the MLT and OLR (a proxy for convection) since water vapor and surface zonal wind do exhibit such a correlation (Figure 5b). On the contrary, our observed result shows small correlation of the ISO between the MLT and OLR at Cariri. Such a discrepancy is possibly due to the distant location of the present site from the convective active source region and may imply its global domination over the local convective condition. Most recently, Guharay et al. (2012) reported less correlation between the OLR and ISO activity during certain times of the three years observational span from an Indian station and indicated some complex mechanisms which might influence the ISO characteristics besides convection.

We have found an indication of the atmospheric tides to drive the ISO in terms of modulation of the water vapor in the TS and tidal amplitude in the MLT. Since the observed correlation between the MLT-ISO and water vapor ISO is high $(>0.5)$, we can infer that the tides generated by water vapor heating and latent heat release are the possible communicators of the tropospheric ISO to the MLT at the present location. As the observed ISO is most likely driven by the eastward 
waves, it is believed that the nonmigrating tides are dominant in the present scenario. Eckermann et al. (1997) concluded that the nonmigrating diurnal tide modulated by the lower atmospheric convectively generated ISO can carry the ISO signature to the mesosphere. Using numerical simulation, Lieberman et al. (2003) showed that the nonmigrating diurnal tides generated by the water vapor heating might communicate the tropospheric variability to the upper mesosphere in the course of their propagation. Isoda et al. (2004) found a dominant role of the convection-driven nonmigrating diurnal tide in the generation of the MLT-ISO. Kumar et al. (2007) observed 20 to 40 day oscillations in the water vapor at an Indian equatorial station indicating an important role of the tides towards driving the MLT-ISO. Gurubaran et al. (2005) concluded that the nonmigrating diurnal tide generated due to latent heat release of water vapor associated with convection could dominate over the migrating component to determine the long-term behavior under certain conditions.

The correlation analysis between the MLT-ISO at various altitudes in the radar zonal wind and TS-ISO in the ERA-Interim zonal wind (Figure 6) suggests that the source region of the MLT-ISO is below $4 \mathrm{~km}$ wherein correlation is found to be maximum. Considerable increase of the correlation coefficients at some altitudes in the TS can be interpreted as enhancement of the ISO activity due to vertically intermittent dissipation of the propagating waves possibly due to local ambient dynamical conditions which require further investigation and could be pursued in our future study.

The estimated mean phase speed of the MJO anomaly in the OLR and surface wind in the troposphere is found to be $4.7 \mathrm{~m} / \mathrm{s}$ in the Indian Ocean-western Pacific region which is very similar to that demonstrated in previous studies. Using OLR, wind, and temperature observations, Hendon and Salby (1994) estimated the eastward MJO anomaly phase speed approximately $5 \mathrm{~m} / \mathrm{s}$ which is very close to the present result. Recently, using OLR and surface wind observations, Yu et al. (2011) calculated the MJO anomaly phase speed to be approximately $4.7 \mathrm{~m} / \mathrm{s}$ resembling the present finding. Yu et al. (2011) investigated the global propagation properties of the MJO, and they showed eastward propagation of the MJO anomaly signature from the Indian Ocean-western Pacific region to the tropical Atlantic through Central America and Panama. However, they did not find any appreciable extension of the MJO over the South American region during the temporal span of 2000-2006 although we have found a very prominent ISO signature in the lower and middle atmosphere in 2008 which may indicate interannual variability of the MJO anomaly propagation extent and the associated dynamics. In the present study, we have found a plausible role of the eastward propagating waves for communicating the ISO signature from lower to middle atmosphere as the lower atmospheric background wind remains westward during January-May. It should be mentioned that during certain times of the year, there may be a possible role of the westward Rossby waves coming from the Indian Ocean region since the present observational location lies close to the western Atlantic. Yu et al. (2011) suggested that the westward propagating Rossby waves could be strong enough due to interaction with the eastward propagating $\mathrm{MJO}$ over the tropical Atlantic region during boreal summer and fall. The westward propagating dominant oscillations of period approximately 25 to 60 days associated with the West African monsoon can influence the tropical Atlantic Ocean dynamics significantly (Thorncroft et al. 2003; Sultan and Janicot 2003).

\section{Conclusions}

The present investigation from an equatorial South American station, Cariri reveals a prominent feature of the ISO in the MLT zonal wind during January-May of 2008 as well as a conspicuous relationship with the lower atmospheric MJO signature indicating lower atmospheric origin. The dominant period of the ISO is found to be approximately 40 to 70 days in the MLT zonal wind and approximately 30 to 60 days in the lower atmospheric variables, i.e., OLR, TCWV, and tropospheric zonal wind. Significant correlation of the ISO between the TCWV and MLT zonal wind as well as modulation of the tidal amplitudes in the ISO period band may suggest a contribution of the atmospheric tides to the existing ISO coupling of the lower and middle atmosphere. The observed smaller correlation of the ISO between the MLT zonal wind and OLR is possibly due to distant location of the present site from the convective anomaly region where the MJO is excited. The ISO amplitude is observed to be significant in the upper troposphere, upper stratosphere, and mid-lower MLT. The MLT-ISO shows evident downward phase progression indicating upward propagation of the dissipating waves responsible for its generation. The high frequency waves with higher phase speeds are surmised to dissipate at higher altitudes. The eastward propagating gravity waves, Kelvin waves, and nonmigrating tides are possibly responsible for driving the ISO at Cariri. The eastward waves are supported by the westward background wind during the enhanced ISO activity period. The excitation of the MLT-ISO is believed to transpire in the lower atmosphere, below $4 \mathrm{~km}$. There is an indication of the vertically intermittent dissipation of the ISO-modulated propagating waves at certain altitudes in the TS which may contribute to the MLT-ISO. The $\mathrm{MJO}$ anomaly signature in the lower atmosphere is found to propagate eastward from the Indian Ocean-western Pacific Ocean to reach the present longitude sector causing ISO activity in the tropical middle atmosphere. 


\section{Competing interests}

The authors declare that they have no competing interests.

\section{Authors' contributions}

AG conceived the ideas and carried out analyses of the work. PPB, RAB, and BRC participated in the observations of the meteor radar. PPB assisted in manuscript preparation. BRC corrected the manuscript. SS assisted in analyses and plotting. All authors read and approved the final manuscript.

\section{Acknowledgements}

AG sincerely acknowledges the support of the Fundação de Amparo a Pesquisa do Estado de São Paulo (FAPESP) to the present research work. The authors are thankful to the NCEP team for providing the OLR data. The authors are grateful to the ECMWF team for providing the ERA-interim dataset which is available at http://apps.ecmwf.int/datasets/data/interim_ full_daily/. The wavelet software used in the present work is provided by C. Torrence and G. P. Compo and available at http://paos.colorado.edu/research/wavelets/.

\section{Author details}

${ }^{1}$ National Institute for Space Research, INPE, São José dos Campos, SP, Brazil. ${ }^{2}$ Department of Physics, Indian Institute of Technology, Roorkee, Uttarakhand, India. ${ }^{3}$ Federal University of Campina Grande, Campina Grande, Paraíba, Brazil.

\section{Received: 9 May 2014 Accepted: 16 October 2014}

\section{Published online: 11 November 2014}

\section{References}

Alexander MJ, Richter JH, Sutherland BR (2006) Generation and trapping of gravity waves from convection with comparison to parameterization. J Atmos Sci 63:2963-2977. doi: http://dx.doi.org/10.1175/JAS3792.1

Baldwin MP, Gray LJ, Dunkerton TJ, Hamilton K, Haynes PH, Randel WJ, Holton JR, Alexander MJ, Hirota I, Horinouchi T, Jones DBA, Kinnersley JS, Marquardt K, Sato K, Takahashi M (2001) The quasi-biennial oscillation. Rev Geophys 39:179-229. doi:10.1029/1999RG000073

Berrisford P, Dee D, Fielding K, Fuentes M, Kallberg P, Kobayashi S, Uppala S (2009) The ERA-Interim Archive. European Centre for Medium Range Weather Forecasts, Shinfield Park, Reading, Berkshire RG2 9AX, United Kingdom, pp 1-16

Burrage MD, Skinner WR, Gell DA, Hays PB, Marshall AR, Ortland DA, Manson AH, Franke SJ, Fritts DC, Hoffman P, McLandress C, Niciejewski R, Schmidlin FJ, Shepherd GG, Singer W, Tsuda T, Vincent RA (1996) Validation of mesosphere and lower thermosphere winds from the high resolution Doppler imager on UARS. J Geophys Res 101(D6):10365-10392. doi:10.1029/95JD01700

Eckermann SD, Vincent RA (1994) First observations of intraseasonal oscillations in the equatorial mesosphere and lower thermosphere. Geophys Res Lett 21:265-268

Eckermann SD, Rajopadhyaya DK, Vincent RA (1997) Intraseasonal wind variability in the equatorial mesosphere and lower thermosphere: long-term observations from the central Pacific. J Atmos Terr Phys 59:603-627

Foltz GR, McPhaden MJ (2004) The 30-70 day oscillations in the tropical Atlantic. Geophys Res Lett 31:L15205. doi:10.1029/2004GL020023

Guharay A, Sekar R, Venkat Ratnam M, Batista PP (2012) Characteristics of the intra-seasonal oscillations in the lower and middle atmosphere over Gadanki. J Atmos Sol Terr Phys 77:167-173. doi:10.1016/j.jastp.2011.12.016

Guharay A, Batista PP, Clemesha BR, Sarkhel S (2013a) On the variability of the terdiurnal tide over a Brazilian equatorial station using meteor radar observations. J Atmos Sol Terr Phys 104:87-95. doi:10.1016/j.jastp.2013.08.021

Guharay A, Batista PP, Clemesha BR (2013b) Study of the ultra-fast Kelvin wave with meteor radar observations over a Brazilian extra-tropical station. J Atmos Sol Terr Phys 102:115-124. doi:10.1016/j.jastp.2013.05.010

Guharay A, Batista PP, Clemesha BR (2014a) On the variability of the seasonal scale oscillations over Cachoeira Paulista $\left(22.7^{\circ} \mathrm{S}, 45^{\circ} \mathrm{W}\right)$, Brazil. Earth Planets Space 66:45

Guharay A, Batista PP, Clemesha BR, Buriti RA (2014b) Observations of the intraseasonal oscillations over two low latitude Brazilian stations: A comparative study. J Atmos Sol Terr Phys 120:62-69. doi:10.1016/j.jastp.2014.08.016

Gurubaran S, Rajaram R, Nakamura T, Tsuda T (2005) Interannual variability of diurnal tide in the tropical mesopause region: a signature of the El Nino-Southern Oscillation (ENSO). Geophys Res Lett 32:L13805. doi:10.1029/2005GL022928
Hagan ME, Forbes JM (2003) Migrating and nonmigrating semidiurnal tides in the upper atmosphere excited by tropospheric latent heat release. J Geophys Res 108(A2):1062. doi:10.1029/2002JA009466

Hendon HH, Salby ML (1994) The life cycle of the Madden-Julian oscillation. J Atmos Sci 51:2225-2237. doi:10.1175/1520-0469(1994) 051<2225: TLCOTM>2.0.CO;2

Hocking WK, Fuller B, Vandepeer B (2001) Real-time determination of meteor related parameters utilizing modern digital technology. J Atmos Sol Terr Phys 63:155-169

Isoda F, Tsuda T, Nakamura T, Vincent RA, Reid IM, Achmad E, Sadewo A, Nuryanto A (2004) Intraseasonal oscillation of the zonal wind near the mesopause observed with medium frequency and meteor radars in tropics. J Geophys Res 109:D21108. doi:10.1029/2003JD003378

Jones C, Waliser DE, Gautier C (1998) The influence of the Madden-Julian Oscillation on ocean surface heat fluxes and sea surface temperature. J Climate 11:1057-1072. doi:10.1175/1520-0442(1998)011<1057:TIOTMJ>2.0.CO;2

Kalnay E, Kanamitsu M, Kistler R, Collins W, Deaven D, Gandin L, Iredell M, Saha S, White G, Woollen J, Zhu Y, Leetmaa A, Reynolds R, Chelliah M, Ebisuzaki W, Higgins W, Janowiak J, Mo KC, Ropelewiski C, Wang J, Jenne R, Joseph D (1996) The NCEP/NCAR 40-year reanalysis project. Bull Am Meteorol Soc 77:437-470

Kumar K, Jain AR (1994) Latitudinal variations of 30-70 day period waves over the tropical Indian zone. J Atmos Terr Phys 56:1135-1145. doi:10.1016/00219169(94)90052-3

Kumar KK, Antonita TM, Ramkumar G, Deepa V, Gurubaran S, Rajaram R (2007) On the tropospheric origin of Mesosphere lower thermosphere region intraseasonal wind variability. J Geophys Res 112:D07109. doi:10.1029/2006JD007962

Lieberman RS (1998) Intraseasonal variability of high-resolution Doppler imager winds in equatorial mesosphere and lower thermosphere. J Geophys Res 103:11221-11228

Lieberman RS, Ortland DA, Yarosh ES (2003) Climatology and interannual variability of diurnal water vapor heating. J Geophys Res 108(D3):4123. doi:10.1029/2002JD002308

Liu Y, Liang XS, Weisberg RH (2007) Rectification of the bias in the wavelet power spectrum. J Atmos Oceanic Tech 24(12):2093-2102

Madden RA, Julian PR (1971) Detection of a 40-50 day oscillation the zonal wind in the tropical Pacific. J Atmos Sci 28:702-708

Madden RA, Julian PR (1972) Description of global-scale circulation cells in the tropics with a 40-50 day period. J Atmos Sci 29:1109-1123

Madden RA, Julian PR (1994) Observations of the 40-50-day tropical oscillation: a review. Mon Weather Rev 122:814-837. doi:10.1175/1520- 493(1994) 122<0814:OOTDTO>2.0.CO;2

Manzini E, Hamilton K (1993) Middle atmospheric traveling waves forced by latent and convective heating. J Atmos Sci 50:2180-2200. doi:http://dx.doi.org/10.1175/1520-0469(1993)050<2180:MATWFB>2.0.CO;2

Miyoshi Y, Fujiwara H (2006) Excitation mechanism of intraseasonal oscillation in the equatorial mesosphere and lower thermosphere. J Geophys Res 111:D14108. doi:10.1029/2005JD006993

Niranjankumar K, Ramkumar TK, Krishnaiah M (2011) Vertical and lateral propagation characteristics of intraseasonal oscillation from the tropical lower troposphere to upper mesosphere. J Geophys Res 116:D21112. doi:10.1029/2010JD015283

Rao RK, Gurubaran S, Sathishkumar S, Sridharan S, Nakamura T, Tsuda T, Takahashi H, Batista PP, Clemesha BR, Buriti RA, Pancheva DV, Mitchell NJ (2009) Longitudinal variability in intraseasonal oscillation in the tropical mesosphere and lower thermosphere region. J Geophys Res 114:D19110. doi:10.1029/2009JD011811

Rokade MV, Kondala Rao R, Nikte SS, Ghodpage RN, Patil PT, Sharma AK, Gurubaran S (2012) Intraseasonal oscillation (ISO) in the MLT zonal wind over Kolhapur $\left(16.8^{\circ} \mathrm{N}\right)$ and Tirunelveli (8.7 $\left.\mathrm{N}\right)$. Ann Geophys 30:1623-1631. doi:10.5194/angeo-30-1623-2012

Sridharan S, Tsuda T, Gurubaran S (2007) Radar observations of long-term variability of mesosphere and lower thermosphere winds over Tirunelveli (8.7 N, 77.8 E). J Geophys Res 112:D23105. doi:10.1029/2007JD008669

Sultan B, Janicot S (2003) The West African monsoon dynamics: part I, documentation of intraseasonal variability. J Climate 16:3389-3406

Thorncroft CD, Parker DJ, Burton RR, Diop M, Ayers JH, Barjat H, Devereau S, Diongue A, Dumelow R, Kindred DR, Price NM, Saloum M, Taylor CM, Tompkins AM (2003) The JET2000 project, aircraft observations of the African easterly jet and African easterly waves. Bull Am Meteorol Soc 79:815-829 
Yu W, Han W, Maloney ED, Gochis D, Xie S-P (2011) Observations of eastward propagation of atmospheric intraseasonal oscillations from the Pacific to the Atlantic. J Geophys Res 116:D02101. doi:10.1029/2010JD014336

Ziemke JR, Stanford JL (1991) One-to-two month oscillations: observed highlatitude tropospheric and stratospheric response to tropical forcing. J Atmos Sci 48:1336-1347. doi:10.1175/1520-0469(1991)048<1336:OTTMOO>2.0.CO;2

doi:10.1186/s40623-014-0145-3

Cite this article as: Guharay et al:: Investigation of the intraseasonal oscillations over a Brazilian equatorial station: a case study. Earth, Planets and Space 2014 66:145

Submit your manuscript to a SpringerOpen ${ }^{\circ}$ journal and benefit from:

- Convenient online submission

- Rigorous peer review

- Immediate publication on acceptance

- Open access: articles freely available online

- High visibility within the field

- Retaining the copyright to your article

Submit your next manuscript at $>$ springeropen.com 